\title{
ANÁLISE DAS CONDIÇÕES DE TRABALHO DE BRIGADISTAS DE COMBATE A INCÊNDIOS FLORESTAIS NO DISTRITO FEDERAL
}

\author{
Nilton César Fiedler ${ }^{1}$ \\ Thiago Oliveira Rodriges ${ }^{2}$ \\ Marcelo Brilhante de Medeiros ${ }^{3}$
}

\begin{abstract}
RESUMO
Esta pesquisa teve como objetivo avaliar as condições de trabalho, treinamento, saúde e segurança dos brigadistas de combate a incêndios florestais no Distrito Federal. A pesquisa foi realizada nas Unidades de Conservação da Fazenda Água limpa, Reserva Ecológica do Instituto Brasileiro de Geografia e Estatística e Instituto Jardim Botânico de Brasília. A coleta de dados foi feita com a aplicação de um questionário em forma de entrevista individual. Participaram da avaliação todos os 53 brigadistas das Unidades de Conservação. De acordo com os resultados obtidos, a brigada do Jardim Botânico de Brasília tinha um alto percentual de treinados $(92,8 \%)$, todos com cursos de primeiros socorros e um alto percentual de trabalhadores com problemas de saúde $(33,3 \%)$. Os brigadistas da Reserva Ecológica do IBGE em sua grande maioria exerciam o trabalho por gosto pela atividade $(84,6 \%)$, eram bem treinados $(92,3 \%)$, todos participaram de cursos de primeiros socorros e o percentual de acidentes foi o mais baixo $(7,7 \%)$. Na brigada da Fazenda Água Limpa foram encontrados os menores percentuais de treinados $(39,1 \%)$, maiores percentuais de acidentes $(17,4 \%)$, menores percentuais de pessoas que exerciam a função por gosto pela atividade $(30,4 \%)$ e menores percentuais de pessoas com problemas de saúde $(8,7 \%)$. A grande maioria dos brigadistas nas três Unidades de Conservação ressaltou a questão da necessidade de regulamentação das brigadas e atentaram para a insatisfação quanto aos equipamentos de proteção individual utilizados e inadequada reposição.

Palavras chave: segurança no trabalho, avaliação ergonômica.
\end{abstract}

\section{ANALYSIS OF JOB CONDITIONS OF THE FOREST FIRE CREW MEMBERS IN DISTRITO} FEDERAL, BRAZIL

\begin{abstract}
This work had as objective to evaluate the job conditions and aspects related to training, health and safety of forest fire crew members in Distrito Federal. The work was carried out at some Protected Areas including Água Limpa Farm, Ecological Reserve of Brazilian Institute of Geography and Statistics (IBGE) and Brasília Botanical Garden. The data was collected through individual interviews with 53 fire crew members. The results shown that the fire crew members of Brasília Botanical Garden had a high number of training for forest fires $(92,8 \%)$, all members obtained first aid courses and there was a high number of health problems $(33,3 \%)$. The fire crew members of IBGE Ecological Reserve shown a high percentage of satisfaction with the activity $(84,6 \%)$ and forest fire training $(92,3 \%)$, all members took first aid courses and there was a low accident rate $(7,7 \%)$. At Água Limpa Farm there were few fire crew members with training $(39,1 \%)$, high percentage of accidents $(17,4 \%)$ and low percentage of health problems $(8,7 \%)$. Most of the fire crew members at the three Protected Areas shown dissatisfaction with the equipment and job regulations.
\end{abstract}

Key-words: job conditions; forest fires.

\section{INTRODUÇÃO}

O combate aos incêndios florestais é trabalho forem precárias, haverá uma atividade notoriamente desgastante em função principalmente da proporção que o fogo pode chegar. Aliado a todo o desgaste físico dos combatentes, se as condições de comprometimento dos níveis de saúde, segurança, bem-estar e satisfação do trabalhador. Esse comprometimento poderá levar a altos índices de acidentes do trabalho,

\footnotetext{
${ }^{1}$ Prof. Adjunto -Enga . Florestal - UnB - C. P. 04357 - CEP 70910-900 Brasília DF - E-mail: fiedler@unb.br

${ }^{2}$ Graduando em Engenharia Florestal - UnB - Bolsista PIBIC - CNPq

${ }^{3}$ Pesquisador EMBRAPA - CENARGEN - E-mail: medeiros@cenargen.embrapa.br

APOIO: Fazenda Água Limpa - UnB; Reserva Ecológica do IBGE; Instituto Jardim Botânico de Brasília.

PESQUISA FINANCIADA PELO CNPq
} 
surgimento de doenças relacionadas ao trabalho, insatisfação, baixa qualidade e produtividade do trabalho. Em pesquisa realizada no Parque Nacional da Serra da Canastra, Fiedler \& Medeiros (2002) concluíram a grande necessidade de aumento da carga horária e da abordagem das disciplinas ministradas nos cursos regulares de treinamento de brigadas para a obtenção de melhores resultados. Um planejamento rigoroso também é preciso, contudo o fogo pode se alastrar com uma velocidade e uma intensidade que qualquer planejamento prévio foge totalmente do controle, e é nesse ponto em que uma equipe bem treinada e equipada faz a diferença, pois ela estará apta a agir com eficiência e rapidez.

Para atingir um nível desejável de treinamento, uma brigada deve buscar essencialmente duas metas: o condicionamento físico e o conhecimento das técnicas e métodos de combate, juntamente ao conhecimento do comportamento do fogo em resposta às condições da região onde a brigada atua (IBAMA 1999).

Esta pesquisa teve como objetivo avaliar as condições de trabalho, treinamento, saúde e segurança dos brigadistas de combate a incêndios florestais em Unidades de Conservação do Distrito Federal.

\section{MATERIAL E MÉTODOS}

A coleta de dados foi feita numa área total de 10.629,63 hectares, na região da APA Gama Cabeça-de-Veado, dentro da Reserva Ecológica do IBGE, Fazenda Água Limpa da Universidade de Brasília e Jardim Botânico de Brasília-DF, localizadas entre as coordenadas $15^{\circ} 55^{\prime} 58^{\prime}$ 'S e 47 51 '02' 'W.

A população estudada foi composta por todos os funcionários (53) das três brigadas de combate a incêndios florestais que atuavam nestas áreas, sendo levantados por meio de questionários. Os questionários foram aplicados por meio de entrevistas individuais aos brigadistas. Os questionários versaram sobre os fatores humanos, as condições de saúde, alimentação, treinamento, reciclagem e segurança no trabalho. A aplicação dos questionários foi realizada utilizando-se a metodologia proposta por Fiedler (1998). A metodologia prevê uma explanação completa sobre os objetivos do trabalho a cada participante de forma individual e aplicação no próprio ambiente de trabalho sem a presença de nenhum outro trabalhador e nem a chefia.

Nas condições de trabalho foram avaliados os riscos na jornada e os pontos que afetam o desempenho no trabalho.

Nas condições de saúde, aspectos como doenças que o trabalhador tem ou teve, possíveis doenças advindas da atividade, afastamentos por motivo de doenças, cansaço ao iniciar a jornada de trabalho e atitude psicológica foram avaliados de acordo com Silva (2001) e Fiedler (1998). Como o nível de escolaridade dos trabalhadores em geral era baixo, a metodologia previa uma explanação mais detalhada sobre situações como as possíveis doenças originadas do trabalho, tipos de cansaços mais comuns e primeiros socorros.

Por último, treinamento e reciclagens na atividade foram levantados quanto à quantidade, qualidade e periodicidade dos treinamentos e reciclagens. Além disso, foram avaliados aspectos de segurança como a disponibilidade e reposição dos equipamentos de proteção individual (EPI).

Foi utilizado o teste qui-quadrado $\left(\chi^{2}\right)$, com nível de significância de 5\%, para verificar as diferenças entre as brigadas quanto ao treinamento e às atividades de combate, através do programa Statistica (2000). Os dados relativos ao treinamento incluíram a freqüência dos brigadistas que receberam treinamento, noções de segurança e primeiros socorros e necessidade de reciclagem. Os dados relativos às atividades de combate aos incêndios florestais incluíram a avaliação dos brigadistas quanto ao EPI utilizado, o horário preferencial de combate e a ocorrência de acidentes.

\section{RESULTADOS E DISCUSSÃO}

\section{Brigada da Fazenda Água Limpa (FAL)}

A parte do trabalho de brigadista que dá maior satisfação é o combate direto com abafador, apontada por $47,8 \%$ dos entrevistados. A menor satisfação é o combate direto com bomba costal, apontada por $26,1 \%$. A função mais difícil e mais perigosa é o combate com ocorrência de virada do vento, com 43,5\% das opiniões. De forma contraditória, embora tenha sido considerada 
por boa parte dos brigadistas como a parte do trabalho que dá maior satisfação, o combate direto com abafador foi considerado como a atividade mais cansativa, com $34,8 \%$ das respostas.

Apenas 39,1\% dos entrevistados da Fazenda Água Limpa afirmaram ter recebido treinamento de brigadista. Todos que receberam treinamento o consideraram satisfatório e estes tiveram em média nove dias de treinamento. Ninguém sentiu dificuldades de atuar como brigadista ao término dos treinamentos e $66,7 \%$ sentem necessidade de relembrar ou aperfeiçoar alguma técnica. Entre todos os entrevistados $65,2 \%$ afirmaram que a Fazenda Água Limpa não realiza cursos ou treinamentos periódicos.

A grande maioria dos brigadistas, representada por $91,3 \%$, revelou não ter tido nenhuma doença grave. Apenas dois brigadistas disseram que tiveram doenças mais graves: um teve pneumonia e o outro tinha fortes e freqüentes dores de cabeça. Os dois representaram $8,7 \%$ do total. Oitenta e seis vírgula nove porcento dos brigadistas afirmaram que atualmente não têm problema de saúde algum e 13\% afirmaram que têm problemas de saúde; um tem problema na visão e dois têm dores constantes na coluna vertebral.

$\mathrm{Na}$ questão relativa a acidentes de trabalho, $82,6 \%$ dos brigadistas responderam que nunca sofreram um acidente no combate ao incêndio. Oitenta e oito vírgula nove porcento dos brigadistas que receberam treinamento também receberam noções de segurança. Apenas 11,1\% consideraram essas noções como não satisfatórias. No caso de noções de primeiros socorros somente 33,3\% dos brigadistas treinados as receberam, e todos as consideraram satisfatórias.

$\mathrm{O}$ equipamento considerado como o mais desconfortável foi a bomba costal com $82,6 \%$ das respostas. O motivo do desconforto que ela causa é o seu peso excessivo confirmado por $78,9 \%$ dos mesmos. A mochila costal e o abafador também foram alvos das reclamações $(17,4 \%)$. Os equipamentos de proteção individual (EPIs) que a Fazenda Água Limpa fornece não são satisfatórios para $65,2 \%$ dos brigadistas porque não há EPIs suficientes para todos. A Fazenda Água Limpa fornece botas para todos os seus funcionários, porém, são inadequadas para o combate a incêndios, pois são de cano curto. Não há calças e camisas próprias para combate, e entre os brigadistas que já usaram a proteção ocular, $40 \%$ consideraram que ela oferece pouca proteção contra a fumaça e o calor. Entre os que já utilizaram a máscara respiratória, 55,5\% a consideraram confortável. A maior parte dos brigadistas, $60,9 \%$ considerou que a reposição dos EPIs não é adequada, deveria ser feita com mais freqüência, uma a duas vezes por ano, preferencialmente antes do período da seca.

Setenta e três vírgula nove porcento dos brigadistas preferem combater incêndios durante o dia. A principal dificuldade no combate durante o dia é o calor representado por $65,2 \%$ das opiniões; à noite é a pouca visibilidade que dificulta o deslocamento e aumenta o risco de acidentes $(95,6 \%)$.

O comentário mais freqüente dos brigadistas é um pedido para que a Brigada adquira mais equipamentos e ferramentas específicos para o combate e de melhor qualidade. Outras sugestões importantes foram a de aquisição de um caminhão pipa, alimentação adequada durante o combate, maior acesso a informações sobre novas tecnologias e novos métodos de combate e a regularização da função de brigadista.

\section{Brigada da Reserva Ecológica do IBGE}

No combate a incêndios a parte mais satisfatória é dividida entre o manuseio da mangueira do caminhão pipa e a condução do caminhão pipa com $23,1 \%$ das opiniões cada. A parte que dá menos satisfação é o combate direto com abafador com $30,8 \%$. A parte considerada como a mais difícil é a situação de fogo intenso com $30,8 \%$ e a parte considerada como a mais perigosa é o momento em que ocorre virada do vento com 38,5\% das respostas. Por fim, a parte considerada como a mais cansativa é o combate direto com abafador relatado por $23,1 \%$ dos brigadistas.

Apenas um brigadista afirmou não ter recebido treinamento, representando $7,7 \%$ do total, enquanto que a grande maioria $(92,3 \%)$ recebeu treinamento, tendo em média 23 dias de treinamento. Todos consideraram $\mathrm{O}$ treinamento satisfatório.

Todos afirmaram não terem dificuldade alguma de atuar como brigadista após o término dos treinamentos e 58,3\% 
responderam não sentirem a necessidade de relembrar ou aperfeiçoar alguma técnica de combate a incêndios. Quarenta e um vírgula sete porcento afirmou que gostaria de realizar uma reciclagem das técnicas aprendidas. Sessenta e nove vírgula dois porcento dos brigadistas afirmaram que a reserva não realiza cursos ou treinamentos com constância.

Do total de brigadistas entrevistados, $30,8 \%$ tiveram alguma doença mais grave no passado (malária, úlcera, problemas na próstata e diabetes). Atualmente $84,6 \%$ não têm problema algum de saúde e $15,4 \%$ apresentam problemas de saúde sendo um caso de ansiedade e outro de problemas na coluna vertebral. Apenas um brigadista sofreu um acidente em um combate direto. Quarenta e seis vírgula um porcento alegaram terem visto acidentes durante o combate. Todos os brigadistas que receberam treinamento tiveram noções de segurança e de primeiros socorros, e todos consideraram essas noções satisfatórias.

A bomba e a mochila costal foram consideradas as ferramentas mais desconfortáveis com $69,2 \%$ das respostas e todos concordaram que o peso é o motivo do desconforto. Apenas 30,8\% consideram os EPIs fornecidos pelo IBGE satisfatórios enquanto $69,23 \%$ consideram os EPIs como não satisfatórios e justificam-se pela falta de equipamentos. O EPI mais desconfortável é a máscara respiratória com $15,4 \%$ das respostas. Porém $61,5 \%$ nunca usaram a máscara. A proteção ocular nunca foi usada por $69,2 \%$ dos brigadistas. As luvas nunca foram utilizadas por $46,2 \%$ dos brigadistas. A reposição dos EPIs não é adequada segundo $61,5 \%$ do total.

Apenas um brigadista prefere $o$ combate noturno em função da temperatura mais amena. As principais dificuldades no combate diurno são os ventos com $38,5 \%$ das respostas e o calor com 53,9\%. A principal dificuldade no combate noturno é a pouca visibilidade.

Os comentários e sugestões mais presentes foram em relação à formalização da brigada e a necessidade de equipamentos e ferramentas adequadas ao combate e de melhor qualidade.

\section{Brigada do Jardim Botânico de Brasília}

Vinte e seis vírgula sete porcento dos brigadistas consideraram como a parte mais satisfatória do trabalho de brigadista o combate direto com abafador e $20 \%$ consideraram o combate direto em geral como a parte menos satisfatória. A parte mais difícil é o combate de fogo em matas de galeria com $26,7 \%$, a parte mais perigosa é a virada do vento com $60 \%$ das respostas, e a parte mais cansativa é o combate em áreas de aclive como morros, com $26,7 \%$ das respostas.

Apenas um brigadista afirmou não ter recebido treinamento e entre os que receberam $92,8 \%$ consideraram-no satisfatório. Eles receberam em média 31 dias de curso. Ninguém sentiu dificuldades de atuar como brigadista após os treinamentos. Cinqüenta porcento sente necessidade de relembrar e aperfeiçoar algumas técnicas de combate e a outra metade dispensa a reciclagem. Quarenta porcento dos brigadistas afirmaram que o JBB realiza cursos e treinamentos periódicos, $26,7 \%$ disseram que às vezes ocorrem cursos ou treinamentos e $33,3 \%$ disseram que não ocorrem.

Entre todos os brigadistas, $80 \%$ nunca tiveram doença. Os demais tiveram problemas de sinusite, pneumonia e úlcera. Atualmente $66,7 \%$ não têm problema de saúde. Entre os brigadistas que têm problemas, $80 \%$ sofrem de pressão alta e $20 \%$ apresentam problemas renais e na coluna vertebral.

Treze vírgula três porcento dos brigadistas do JBB já sofreram acidente na função. Quarenta e seis vírgula sete porcento já presenciaram algum acidente na função.

Entre os que receberam treinamento, todos tiveram noções de segurança e de primeiros socorros. Sete vírgula um porcento não consideraram as noções de segurança satisfatórias e 14,3\% não consideraram as de primeiros socorros satisfatórias.

A bomba costal foi considerada o equipamento mais desconfortável segundo $80 \%$ dos brigadistas, seguidos da mochila costal $(66,7 \%)$ e do abafador $(53,3 \%)$. O principal motivo do desconforto foi o peso conforme a opinião de $53,3 \%$ dos brigadistas. Os EPIs não foram satisfatórios para $66,7 \%$ dos entrevistados. Alguns equipamentos básicos como calça e camisas foram 
considerados como desconfortáveis por serem inadequados para a atividade. Cinqüenta e três vírgula três porcento dos brigadistas que já utilizaram a proteção ocular consideraram-na a desconfortável por ineficiência e incômodo. A máscara respiratória foi considerada desconfortável por $13,3 \%$ deles. As luvas foram consideradas desconfortáveis por $46,7 \%$ deles por serem incômodas e inadequadas. Setenta e três vírgula três porcento consideraram a reposição dos EPIs inadequada. O combate diurno foi preferido por $86,7 \%$ dos brigadistas. O calor e o vento são as principais dificuldades do combate diurno, ambas com $60 \%$ das respostas. A pouca visibilidade é a principal dificuldade do combate noturno.

Os brigadistas do JBB levantam a questão da necessidade de regulamentação das Brigadas e atentam para a falta de material de segurança e a necessidade de se criar um fundo específico para as Brigadas no repasse das verbas concedidas pelo governo.

\section{Análise de Diferenças Entre as Brigadas}

As figuras 1 e 2 mostram uma comparação dos principais fatores de diferença entre as brigadas em relação aos itens de treinamento, combate e satisfação com equipamentos. Nota-se que o baixo índice de treinamento e baixa participação em cursos de primeiros socorros dos brigadistas da Fazenda Água Limpa provavelmente tem levado a um maior índice de acidentes (figura 1). As considerações sobre a falta de equipamentos de proteção individual e reposição inadequada foram constantes em todas as brigadas avaliadas (figura 2).

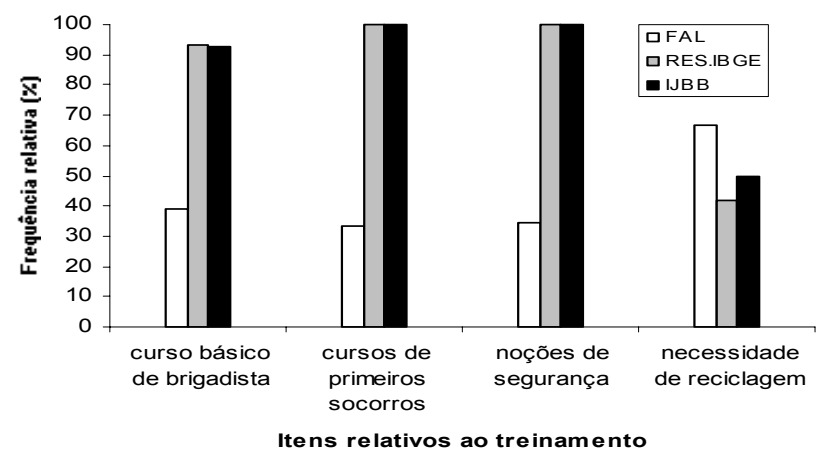

Figura 1: Diferenças entre as brigadas quanto a aspectos de treinamento

Figure 1: Differences among fire crews related to training aspects

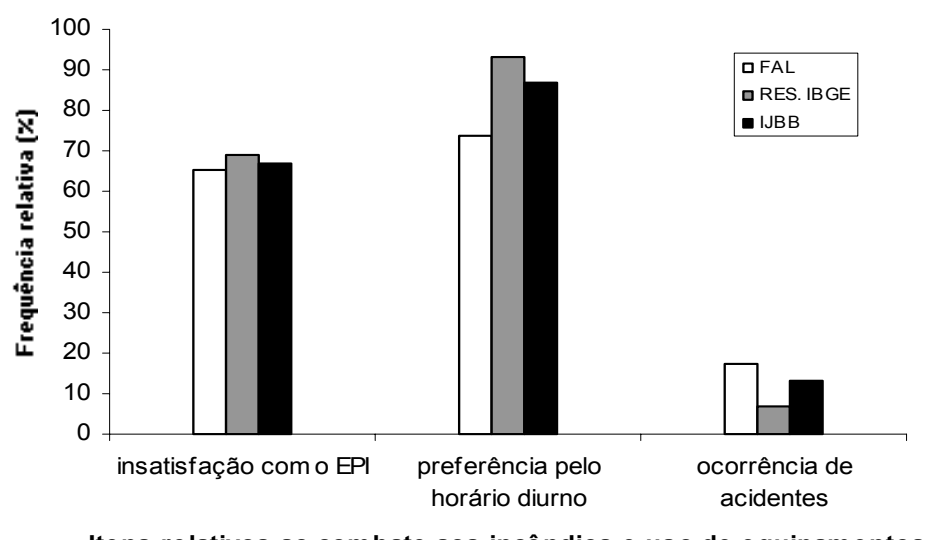

Figura 2: Diferenças entre as brigadas quanto a aspectos de combate aos incêndios e equipamentos

Figure 2: Differences among fire crews related to fire fighting and equipments 
De acordo com a avaliação estatística, foram observadas diferenças significativas $\left(\chi^{2}\right.$ $=37,27 ; \mathrm{p}<0,05)$ entre as brigadas para os itens relativos ao treinamento (noções de primeiros socorros, número de treinados, necessidade de reciclagem e noções de segurança). $\mathrm{O}$ item relativo ao número de brigadistas que receberam treinamento foi importante para as diferenças, considerando que há uma grande deficiência de treinamento para os brigadistas da Fazenda Água Limpa. De qualquer forma, as três brigadas analisadas necessitam de treinamentos complementares ao curso básico que foi oferecido, assim como já foi observado para as brigadas no Parque Nacional Serra da Canastra (Fiedler \& Medeiros 2002).

Para os itens relativos às atividades de combate aos incêndios, incluindo insatisfação com o EPI, preferência pelo horário diurno e ocorrência de acidentes não houve diferenças significativas $\left(\chi^{2}=0,18 ; p>0,05\right)$.

Particularmente a insatisfação generalizada dos brigadistas com o EPI demonstra a necessidade de adaptação e aquisição de equipamentos mais confortáveis e práticos. A carência e a inadequação de equipamentos também parece ser comum a muitas brigadas de combate a incêndios florestais no Brasil, sendo este item um dos principais responsáveis pelo baixo grau de eficiência das atividades de combate (Fiedler $\&$ Medeiros 2002; Medeiros 2002).

\section{CONCLUSÕES}

De acordo com os resultados obtidos, conclui-se que:

- Há necessidades de melhoria na reposição de equipamentos de proteção individual e estabelecimento de reciclagens mais periódicas para todas as brigadas e, particularmente, para a brigada da Fazenda Água Limpa, onde foi registrado o maior número de acidentes;
- O equipamento de combate considerado mais desconfortável pelos brigadistas foi a bomba costal em função das suas condições anatômicas e peso;

- As brigadas analisadas apresentaram diferenças significativas quanto ao treinamento e não apresentaram diferenças significativas quanto às atividades de combate.

\section{REFERÊNCIAS}

FIEDLER, N. C. (1998). Análise de Posturas e Esforços despendidos em operações de Colheita Florestal. Viçosa, UFV. 106 p. (Tese de Doutorado).

FIEDLER, N. C.; MEDEIROS, M. B. (2002). Plano de prevenção e combate a incêndios florestais para o Parque Nacional da Serra da Canastra. Brasília: IBAMA. 75 p.

IBAMA (1999). Manual de prevenção e combate aos incêndios florestais. Apostila. Brasília. 180 p.

MINETTI, L.J. (1996) Análise de fatores operacionais e ergonômicos na operação de corte florestal com motosserra. Viçosa: UFV, 211 p. Tese de Doutorado, Universidade Federal de Viçosa.

MEDEIROS, M. B. (2002). Manejo do Fogo em Unidades de Conservação do Cerrado. Boletim do Herbário Ezechias Paulo Heringer. 10: 76-89.

SILVA, J. C. (2001) Diagnóstico das áreas de maior incidência de incêndios florestais em unidades de conservação pertencentes a APA Gama Cabeça-de-veado. Brasília, Universidade de Brasília (Dissertação de Mestrado). 59 p.

STATISTICA. (2000). StatSoft Inc. Tulsa 